\title{
Dual-wavelength linear depolarization ratio of volcanic aerosols: Lidar measurements of the Eyjafjallajökull plume over Maisach, Germany
}

\author{
Silke Groß*, Volker Freudenthaler, Matthias Wiegner, Josef Gasteiger, Alexander Geiß, Franziska Schnell \\ Meteorological Institute, Ludwig-Maximilians-Universität, Theresienstr. 37, 80333 Munich, Germany
}

\section{A R T I C L E I N F O}

\section{Article history:}

Received 10 February 2011

Received in revised form

27 May 2011

Accepted 7 June 2011

\section{Keywords:}

Volcanic ash

Lidar measurements

Depolarization

Lidar ratio

Remote sensing

\begin{abstract}
A B S T R A C T
The ash plume of the Eyjafjallajökull eruption in April 2010 offered an exceptional opportunity to assess the potential of advanced lidar systems to characterize the volcanic aerosols. Consequently, the plume was continuously observed in the framework of EARLINET. In this paper we focus on the EARLINETRaman-depolarization-lidar measurements at Maisach near Munich, Germany. From these data sets the lidar ratio $S_{\mathrm{p}}$ and the particle linear depolarization ratio $\delta_{\mathrm{p}}$ at two wavelengths ( $355 \mathrm{~nm}$ and $532 \mathrm{~nm}$ ) were retrieved. These quantities can be used to characterize volcanic aerosols and to establish criteria for the discrimination from other aerosol types. In the pure volcanic ash plume, observed until noon of 17 April, wavelength independent values of $\delta_{\mathrm{p}}$ as high as $0.35<\delta_{\mathrm{p}}<0.38$, indicating non-spherical particles, were found, and lidar ratios of $50<S_{\mathrm{p}}<60 \mathrm{sr}$ at $355 \mathrm{~nm}$ and $45<S_{\mathrm{p}}<55$ sr at $532 \mathrm{~nm}$. Later, volcanic aerosols were mixed into the boundary layer. This mixture showed in general lower values of $\delta_{\mathrm{p}}$ as expected from the contribution of boundary layer aerosols. Especially noteworthy is the increase of $\delta_{\mathrm{p}}$ with wavelength, when volcanic ash was mixed with small spherical particles.
\end{abstract}

(c) 2011 Elsevier Ltd. All rights reserved.

\section{Introduction}

Particles and gases released from volcanic eruptions can significantly influence climate on continental or even global scale as they have an influence on the radiation budget of the Earth (Robock, 2000) and the hydrological cycle (Trenberth and Dai, 2007). The eruption of Pinatubo on the Philippines in 1991, led to a global cooling of the troposphere of $0.5 \mathrm{~K}-0.8 \mathrm{~K}$ in the following year (Parker et al., 1996). The strongest eruption in modern times, the Tambora on Java in 1815 , led to a reduction of the tropospheric temperature of up to $3 \mathrm{~K}$ in parts of the northern hemisphere in the subsequent summer (Rampino and Self, 1982). Compared to these events the impact of the eruption of the Eyjafjallajökull between 14 April and 23 May 2010 on the Earth's climate was small, as the amount of ash and sulfur dioxide injected into the stratosphere was low. The ash plume only rose up to about $8 \mathrm{~km}$ height (IES: Inst. of Earth Sciences, Univ. of Iceland; http:// www.earthice.hi.is). However, the eruption had significant consequences for aviation over Europe and thus a severe economic impact. During the first phase (16-21 April) Central Europe and the UK were affected, whereas during the second phase (5-11 May) mainly air

\footnotetext{
* Corresponding author. Present address: Institut für Physik der Atmosphäre, Deutsches Zentrum für Luft- und Raumfahrt (DLR), Münchner Str. 20, 82234 Weßling, Germany.

E-mail address: silke.gross@dlr.de (S. Groß).
}

traffic over UK and the Iberian Peninsula was disrupted. The reason is that significant amounts of ash are expected to damage aircraft engines. The decision on air space closure was based on the zerotolerance rule of the ICAO. The relevant model calculations (Jones et al., 2007) of the ash dispersion were performed by the VAAC (Volcanic Ash Advisory Center) at the British Met Office. These decisions were heavily discussed arguing that no measurements were available for justification. In this context the European Aerosol Research Network EARLINET (Boesenberg, 2003) proved its potential to monitor the 4d-distribution of the volcanic ash plume by means of coordinated lidar measurements. Lidar measurements are a well established tool for volcanic aerosol research as has been shown e. g. by the long-term observations of stratospheric volcanic aerosols over Central Europe since 1976 (Jaeger, 2005), and studies on volcanic aerosols in the lower stratosphere with a multi-wavelength Raman lidar system (Mattis et al., 2010). Wang et al. (2008) used lidar data from different EARLINET stations for the characterization of volcanic ash from Etna eruptions. The volcanic gas-particle mixture undergoes modifications of its micro-physical, optical and chemical properties during the transport. Large particles fall out rapidly near the eruption site, whereas fine particles and trace gases, e.g. $\mathrm{SO}_{2}$, can be transported over long distances and can remain in the troposphere for several weeks (Ovadnevaite et al., 2009). Aerosols include e.g. hygroscopic droplets as sulfuric acid, as well as hydrophobic particles of glass and minerals. Moreover, internal mixtures are not unlikely. The state of particles can be identified from lidar depolarization 
measurements because of their non-spherical shape. For example, Sassen et al. (2007) used linear depolarization ratio measurements for the identification of volcanic ash over Alaska.

However, measurements of volcanic ash properties under ambient conditions are still rare. In particular, approaches to distinguish volcanic ash from other, less harmful aerosols are lacking. In this study we investigate the potential to use the linear depolarization ratio $\delta_{\mathrm{p}}$ and the lidar ratio $S_{\mathrm{p}}$, both being bulk properties of aerosols, for this purpose. This option is realistic only recently, as only in the last years high quality depolarization measurements became available. In this paper we rely on dualwavelength Raman- and depolarization measurements of volcanic aerosols from the Eyjafjallajökull eruption. Observations were performed at Maisach ( $48.209 \mathrm{~N}, 11.258 \mathrm{E}, 516 \mathrm{~m}$ asl), a rural site $25 \mathrm{~km}$ north-west of Munich. Pure volcanic ash as well as volcanic ash mixed with boundary layer aerosols were observed, so the relevant stages of the event were covered. In Section 2 we describe our instrumentation and the methodology of our data evaluation. Then we substantiate the selected periods of measurements (Section. 3). The next Section focuses on the discussion of the retrieved optical properties, and their potential for the identification of ash in aerosol mixtures. A short summary concludes this work.

\section{Instrumentation and data evaluation}

The two Raman- and depolarization-lidar systems MULIS (Multi wavelength lidar system) (Freudenthaler et al., 2009) and POLIS (Portable Lidar System) (Groß et al., 2008) are developed and operated by the Meteorological Institute of the Ludwig-Maximilians-Universität, München, (MIM) and act as reference lidar systems in the lidar network EARLINET. MULIS measures elastically backscattered light at $355 \mathrm{~nm}, 532 \mathrm{~nm}$ and $1064 \mathrm{~nm}$, and backscattering from the RAMAN shifted radiation (vibrational band of $\mathrm{N}_{2}$ ) at $387 \mathrm{~nm}$ and $607 \mathrm{~nm}$. The linear depolarization ratio at $532 \mathrm{~nm}$ is derived from the cross- and co-polarized (with respect to the polarization plane of the emitted laser radiation) signals. MULIS provides full overlap at about $200 \mathrm{~m}-400 \mathrm{~m}$, depending on the system settings. POLIS, a small, two channel lidar system, can be operated in two configurations, either in the Raman-mode measuring elastic backscattered and $\mathrm{N}_{2}$-Raman shifted light at $355 \mathrm{~nm}$ and $387 \mathrm{~nm}$, respectively, or in the depolarization-mode with linear cross- and co-polarized signals at $355 \mathrm{~nm}$. The full overlap height is at about $70 \mathrm{~m}$. As both systems were operated at the same site during this event, POLIS measurements were performed in the depolarization-mode to have simultaneously $\delta_{\mathrm{p}}$ at $355 \mathrm{~nm}$ and $532 \mathrm{~nm}$ by combining both data-sets. The rangeresolution of the raw data of both lidars is $7.5 \mathrm{~m}$, and the temporal average of the raw data is $10 \mathrm{~s}$. Measurements were performed under an elevation angle of $85^{\circ}$ (MULIS) and $75^{\circ}$ (POLIS).

The signal analysis applying the Raman-methodology (Ansmann et al., 1992) provides independent profiles of the particle extinction coefficient $\alpha_{\mathrm{p}}$ and of the backscatter coefficient $\beta_{\mathrm{p}}$. Thus, profiles of the lidar ratio $S_{\mathrm{p}}=\alpha_{\mathrm{p}} / \beta_{\mathrm{p}}$ can readily be derived. The signal-to-noise ratio of Raman measurements is comparably low. As a consequence, our measurements of the Raman signals at $387 \mathrm{~nm}$ and $607 \mathrm{~nm}$ are restricted to night-time; the high solar background inhibits the application of the method during daytime. To increase the signal-tonoise ratio we evaluate time averages of one to two hours, taking care of the, temporal stability within the corresponding time period. To further increase the signal-to-noise ratio, the raw signals are smoothed over range, making sure that the elastic and inelastic signals are smoothed with the same window length. The typical smooth-length is $280 \mathrm{~m}$. With respect to height, the smoothing length is reduced by the sine of the lidar elevation angle. For special applications we also use the Klett-Fernald (Fernald, 1984) inversion algorithm. The required input parameter, $S_{\mathrm{p}}$, is taken from Raman inversions. Though this procedure is not fully consistent, it has the advantage to provide profiles from the overlap range and the vertical resolution is improved.

It is convenient to calculate the linear volume depolarization ratio $\delta_{\mathrm{V}}$ as a first approximation of $\delta_{\mathrm{p}}$, because $\delta_{\mathrm{V}}$ can be directly derived from the co- $\left(P_{\|}\right)$and cross-polarized $\left(P_{\perp}\right)$ returns provided that the calibration factor $C$ is known.

$$
\delta_{\mathrm{V}}=C \frac{P_{\perp}}{P_{\|}}
$$

The co-polarized signal is detected in the reflected branch of the polarizing beam-splitter cube to decrease channel cross talk. Polarizing filter behind the beam-splitter cube additionally suppress cross-talk, which reduces the error of the depolarization ratio. The calibration factor $C$ was determined from dedicated calibration measurements, and accounts for the transmission of all optics and filters, the diattenuation of the polarizing beam-splitter cube, and the electronic amplification of the photomultipliers and preamplifiers. For both systems, MULIS and POLIS, the determination of $C$ is performed according to the very accurate $\pm 45^{\circ}$-calibration method (Freudenthaler et al., 2009) using a half-wave-plate (MULIS) and manual rotation (POLIS).

The determination of the particle linear depolarization ratio $\delta_{\mathrm{p}}$ requires a more complex procedure. It can be calculated according to Biele et al. (2000)

$\delta_{\mathrm{p}}=\frac{\left(1+\delta_{\mathrm{m}}\right) \delta_{\mathrm{v}} R-\left(1+\delta_{\mathrm{v}}\right) \delta_{\mathrm{m}}}{\left(1+\delta_{\mathrm{m}}\right) R-\left(1+\delta_{\mathrm{v}}\right)}$

with the backscatter ratio $R$ defined as

$R=\frac{\beta_{\mathrm{m}}+\beta_{\mathrm{a}}}{\beta_{\mathrm{m}}}$

The height dependent particle backscatter coefficient $\beta_{\mathrm{p}}$ is retrieved with the Fernald inversion scheme (Fernald, 1984) using the lidar ratio $S_{\mathrm{p}}$ derived from the Raman-methodology mentioned above. The molecular linear depolarization ratio $\delta_{\mathrm{m}}$ is calculated taking into account the actual bandwidth of the interference filter (Behrendt and Nakamura, 2002), and the molecular backscatter coefficient $\beta_{\mathrm{m}}$ is calculated using data from radiosondes of the German Weather Service launched in Oberschleißheim, which is only $22 \mathrm{~km}$ east of Maisach. The errors of $\delta_{\mathrm{p}}$ are calculated according to Freudenthaler et al. (2009), the errors of $S_{\mathrm{p}}$ are calculated according to Groß et al. (2011a).

As a result, the linear depolarization ratio and the lidar ratio of volcanic ash $\left(\delta_{\mathrm{a}}\right.$ and $\left.S_{\mathrm{p}, \mathrm{a}}\right)$ can be determined at two wavelengths. On the one hand, this is the basis for the development of criteria to unambiguously describe volcanic ash, on the other hand, it is the prerequisite of the characterization the contribution of ash with respect to extinction and mass concentration in cases when ash has been mixed into the boundary layer. The second application is briefly outlined in the following:

Assuming a two component aerosol mixture of ash particles (subscript a) and non-ash particles (subscript na), the contribution of the ash-related component to the total backscatter coefficient, $\varepsilon_{\mathrm{b}}=\beta_{\mathrm{a}} / \beta_{\mathrm{p}}$, can be derived following a procedure described by Tesche et al. (2009). It is based on lidar measurements of the linear depolarization ratio $\delta_{\mathrm{p}}$ and the backscatter coefficient $\beta_{\mathrm{p}}$.

$\varepsilon_{\mathrm{b}}=\frac{\left(\delta_{\mathrm{p}}-\delta_{\mathrm{na}}\right)\left(1+\delta_{\mathrm{a}}\right)}{\left(\delta_{\mathrm{a}}-\delta_{\mathrm{na}}\right)\left(1+\delta_{\mathrm{p}}\right)}$ 
Input parameters required to solve Eq. (4) are $\delta_{\text {na }}$ and $\delta_{\mathrm{a}}$ : the former depends on the non-ash aerosol type present in the boundary layer and is known from previous measurements, whereas the latter is taken from observations of the 'pure' volcanic ash layer as will be described in Section 4. Using additionally the lidar ratio of the 'pure' volcanic ash $S_{\mathrm{p}, \mathrm{a}}$ (see also Section 4), the extinction coefficient of volcanic ash $\alpha_{\mathrm{a}}$ and the mass concentration $M_{\mathrm{a}}$ can be derived according to

$M_{\mathrm{a}}=\eta_{\mathrm{a}} \alpha_{\mathrm{a}}=\eta_{\mathrm{a}} S_{\mathrm{p}, \mathrm{a}} \beta_{\mathrm{a}}$

where $\eta_{\mathrm{a}}$ is the conversion factor from extinction to mass concentration for volcanic ash. We us $\eta_{\mathrm{a}}=1.55 \mathrm{gm}^{-2}$ at $355 \mathrm{~nm}$ and $\eta_{\mathrm{a}}=1.45 \mathrm{gm}^{-2}$ at $532 \mathrm{~nm}$ according to Gasteiger et al. (2011). The relative uncertainty of the retrieved mass concentration is estimated to be in the order of $40 \%$ and mainly caused by the uncertainty of the micro-physics of the particles (size distribution, refractive index and shape).

Applying a similar approach as described by Eq. (4), however, using $S_{\mathrm{p}}$ instead of $\delta_{\mathrm{p}}$, we can derive the relative contribution of ash with respect to extinction, i.e., $\varepsilon_{\mathrm{a}}=\alpha_{\mathrm{a}} / \alpha_{\mathrm{p}}$, according to:

$\varepsilon_{\mathrm{a}}=\frac{S_{\mathrm{a}}\left(S_{\mathrm{na}}-S_{\mathrm{p}}\right)}{S_{\mathrm{p}}\left(S_{\mathrm{na}}-S_{\mathrm{a}}\right)}$

As a brief summary of this section we want to point out, that the determination of the contributions of a two-component aerosol mixture is primarily based on measurements of the depolarization ratio $\delta_{\mathrm{p}}$. The reason for selecting this approach is that depolarization is comparably easy to measure (provided, the lidar system is carefully calibrated) and that $\delta_{\mathrm{p}}$-profiles can be derived with high vertical resolution. In principle, it is also possible to use the lidar ratio for this purpose, though the spatial resolution is worse and the approach is limited to night-time observations. Nevertheless, we use $S_{\mathrm{p}}$ (see Eq. (6)) as an independent check of the plausibility of our retrieval based on the depolarization ratio.

\section{Overview over measurements}

On 14 April 2010, explosive eruptions of the Eyjafjallajökull (63.63 N, $19.63 \mathrm{~W}$ ) started. The ash plumes reached heights up to $8 \mathrm{~km}$. A northwesterly flow transported ash loaded air-masses to Central Europe (Emeis et al., 2010). The ash plume reached Northern Germany in the night from 15 April to 16 April (Flentje et al., 2010; Ansmann et al., 2010). Southern Germany was affected roughly twelve hours later. Fig. 1 displays the temporal development of the volcanic plume over Maisach from 16 April 17 UTC to 17 April 24 UTC as monitored by MULIS; shown is the range corrected signal (logarithmic scale - upper panel) and the volume linear depolarization ratio $\delta_{\mathrm{v}}$ (lower panel), both being quantities that were derived in near real-time. Whereas the signature shown in the upper panel clearly demonstrates the existence of a pronounced aerosol layer, the large values of $\delta_{\mathrm{v}}$ are a clear indication of non-spherical particles and a typical feature of volcanic ash. Rain and clouds on top of the boundary layer prevented the observation of the volcanic plume only during short time periods (blank areas). The volcanic plume could first be detected on 16 April at about 17 UTC in heights from $5 \mathrm{~km}$ to $7 \mathrm{~km}$ above ground level (note that henceforward all altitudes are given
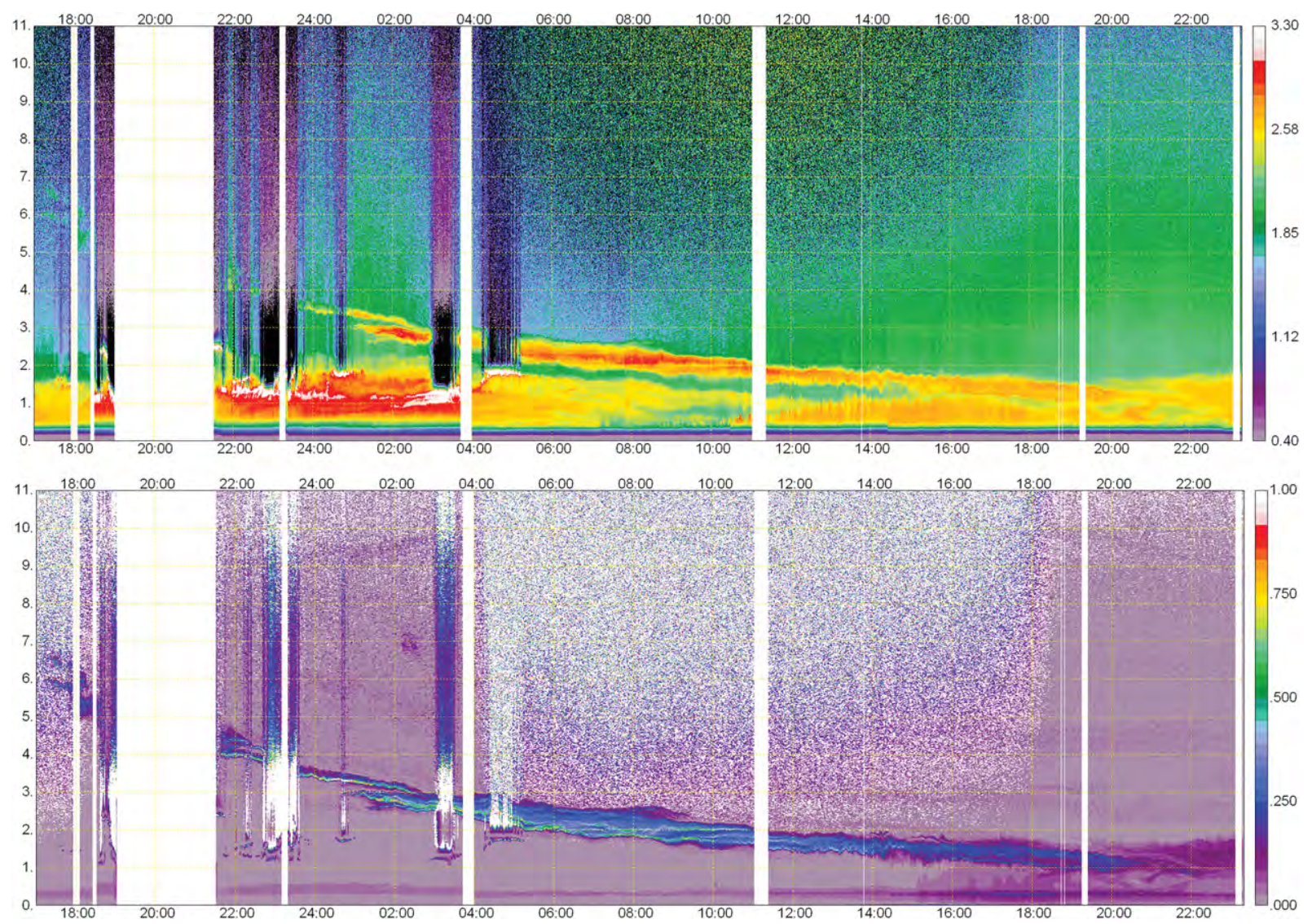

Fig. 1. Time-height cross section of the range-corrected signal (upper panel, log-scale, a.u.) and the volume linear depolarization ratio (lower panel) at 532 nm derived from MULIS lidar measurements at Maisach from 16 April 17 UTC to 17 April 24 UTC. 

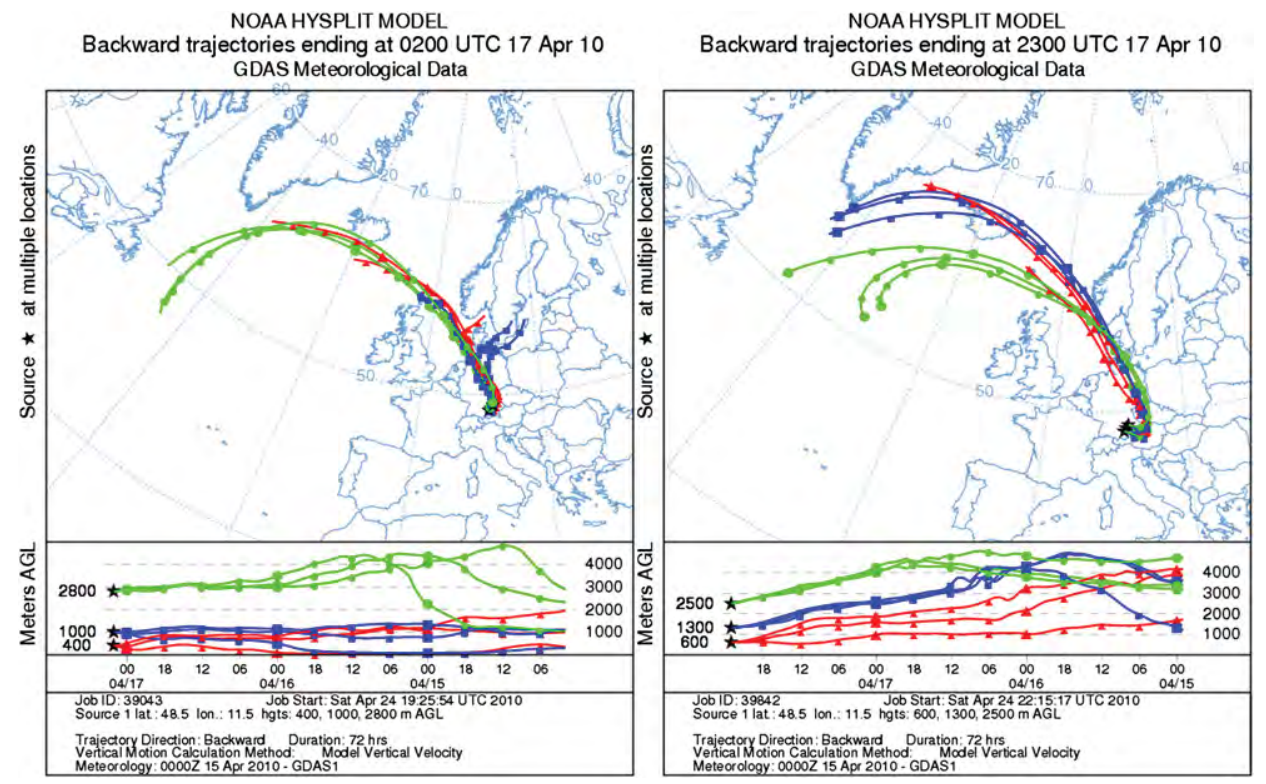

Fig. 2. 72-h HYSPLIT backward trajectories ending in Maisach on 17 April 201002 UTC (left) at $400 \mathrm{~m}, 1000 \mathrm{~m}$ and $2800 \mathrm{~m}$, and 23 UTC (right) at $600 \mathrm{~m}$, $1300 \mathrm{~m}$ and $2500 \mathrm{~m}$ (all heights above ground level).

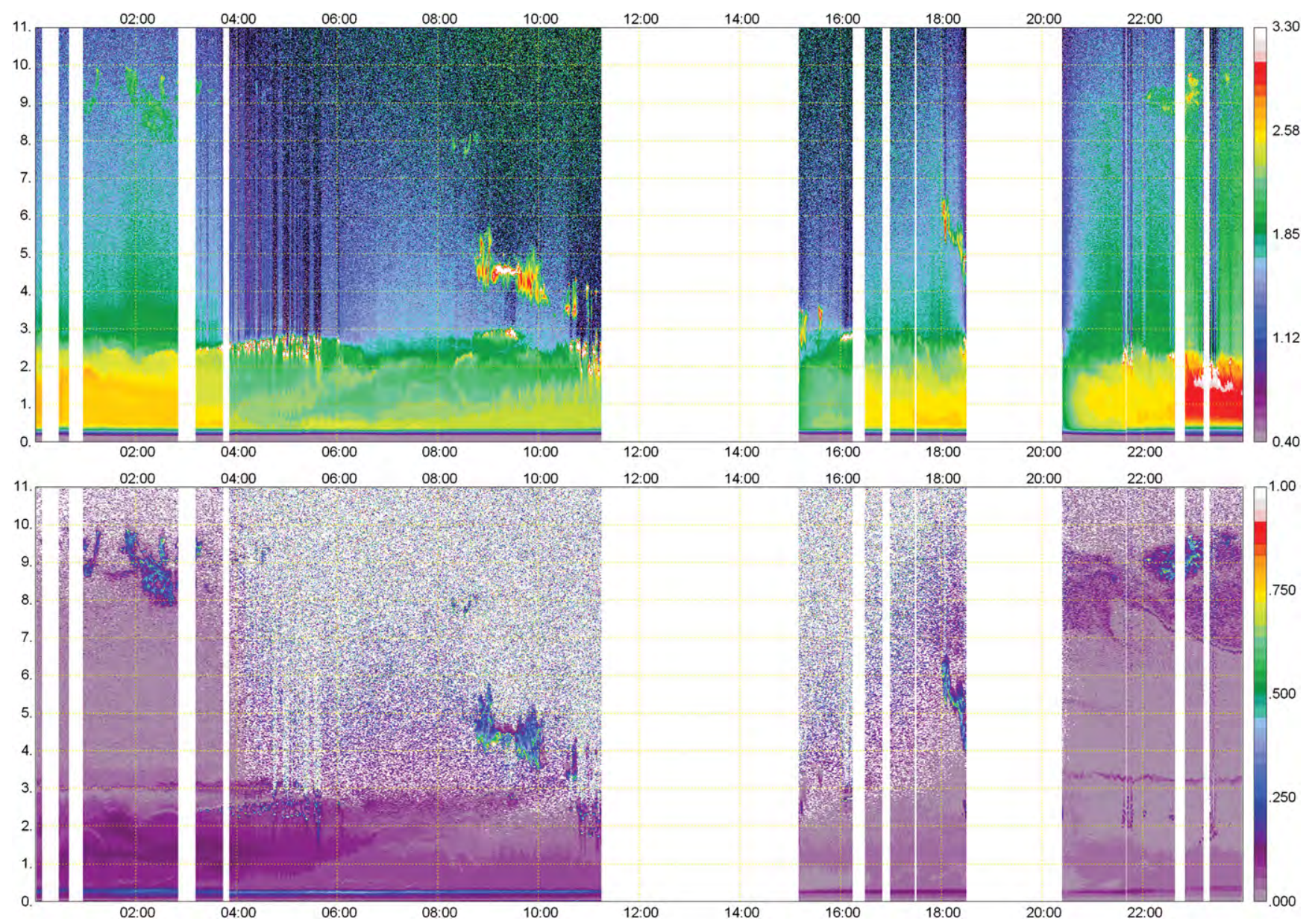

Fig. 3. Time-height cross section of the range-corrected signal (upper panel, log-scale, a.u.) and the volume linear depolarization ratio (lower panel) at 532 nm derived from MULIS lidar measurements at Maisach from 20 April 00 UTC to 24 UTC. 
above ground level), as is obvious from the volume linear depolarization ratio. It descended to $4 \mathrm{~km}$ at midnight and to less than $2.5 \mathrm{~km}$ after $11 \mathrm{UTC}$, mainly due to subsidence of the air mass (Wiegner et al., 2011). After 16 UTC the volcanic plume started to entrain into the boundary layer. The maximum extinction coefficient of the plume was measured around 07 UTC on 17 April at an altitude between $2.0 \mathrm{~km}$ and $2.4 \mathrm{~km}$ with wavelength independent values as high as $0.75 \mathrm{~km}^{-1}$ (Groß et al., 2010). Inversion of the lidar derived optical parameters results in a maximum mass concentration of about $1.1 \mathrm{mg} \mathrm{m}^{-3}$ (Gasteiger et al., 2011). Our conclusion that the pronounced layer was the ash plume of Eyjafjallajökull is supported by HYSPLIT backward trajectories (Fig. 2) that demonstrate that the origin of the lofted layer - here shown for 17 April at 02 UTC at an altitude of $2.8 \mathrm{~km}$ (green line in left panel) - and of the aerosol mixture in the boundary layer at 23 UTC (red and blue lines in right panel) was indeed located in Iceland. We want to emphasize that an overview over the dispersion of the plume requires the inspection of the time-height cross sections of the range corrected signal and the volume linear depolarization ratio. Doing this, volcanic aerosols could be found throughout the troposphere, in lofted layers or mixed into the boundary layer, from 16 April to 25 April. As one example of the complexity of the vertical structure and for the requirement of both quantities, Fig. 3 shows the measurements of 20 April. It is obvious that the range corrected signal is not sufficient to trace the volcanic ash layers, in particular during the morning hours. However, considering also $\delta_{\mathrm{v}}$ we can detect ash particles mixed into the boundary layer and just above. This finding was again supported from back trajectory analysis (Fig. 4 - red and blue lines) showing that the origin of the airmasses was still Iceland. In the afternoon and at night time ash

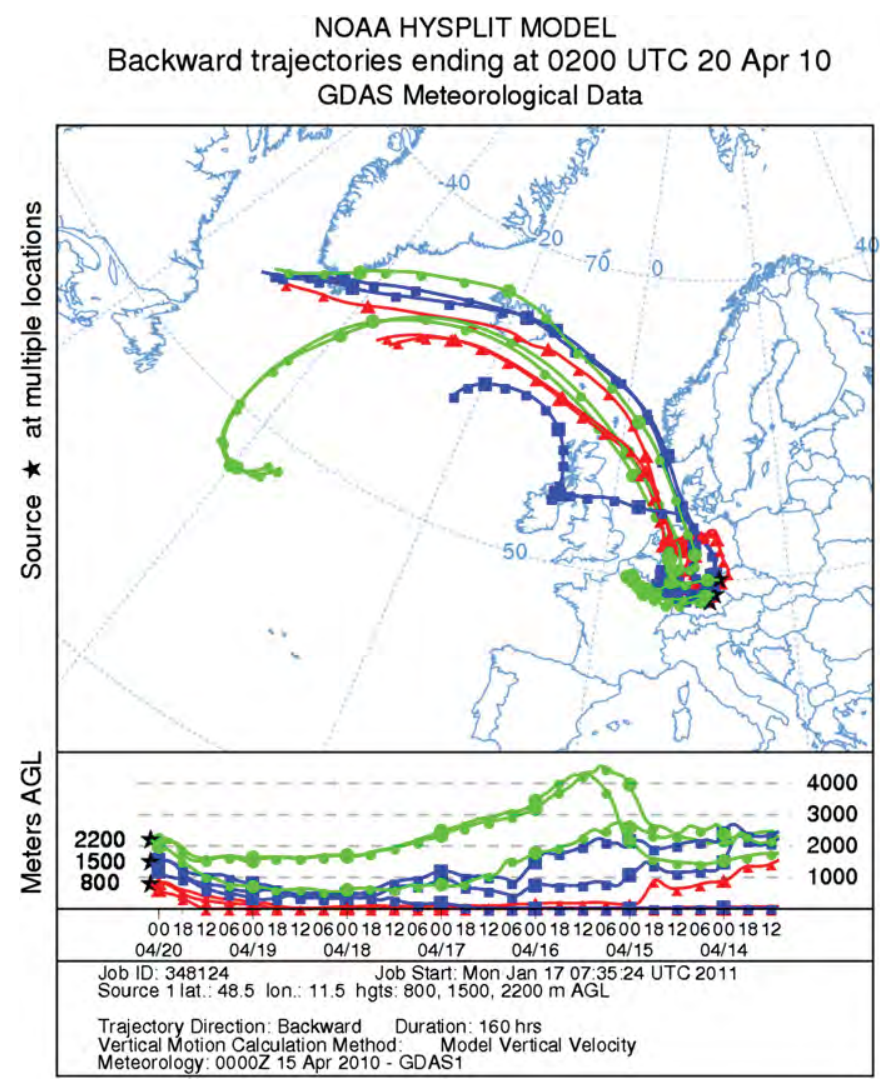

Fig. 4. 160-h HYSPLIT backward trajectories ending in Maisach on 20 April, 2010 02 UTC at $800 \mathrm{~m}, 1500 \mathrm{~m}$ and $2200 \mathrm{~m}$ above ground level. was also visible in the upper troposphere as optically thin filaments up to $10 \mathrm{~km}$ (see Fig. 3).

Based on these cross sections we selected three different observation periods to find criteria suitable to distinguish pure volcanic ash from other aerosol types and to cover different mixing states of the ash layer over Southern Germany. For the pure volcanic ash case we selected the slot from 01:30 UTC - 02:40 UTC on 17 April (period I). For the 'mixed case' we selected two intervals: 17 April, 22:00 UTC - 23:00 UTC (period II) and 20 April, 01:00 UTC - 02:50 UTC (period III); period II was selected from the first phase of the eruption when primarily ash was emitted, whereas period III is from the second phase of the event, when significant amounts of sulfur were emitted (Magnus et al., 2010).

\section{Retrieval of optical properties}

The characterization of volcanic aerosols from the Eyjafjallajökull eruption includes the backscatter coefficient $\beta_{\mathrm{p}}$, the extinction coefficient $\alpha_{\mathrm{p}}$, the lidar ratio $S_{\mathrm{p}}$, and the particle linear depolarization ratio $\delta_{\mathrm{p}}$ at $355 \mathrm{~nm}$ and $532 \mathrm{~nm}$. Profiles of $\alpha_{\mathrm{p}}$ and $S_{\mathrm{p}}$ derived with the Raman method for the three selected time periods are shown in Figs. 5, 8 and 11, whereas in Figs. 6, 9 and 12 the optical properties $\beta_{\mathrm{p}}$ and $\delta_{\mathrm{p}}$ are plotted. Period I (17 April from 01:30 UTC $02: 40$ UTC) is an example from the time interval when the ash layer over Maisach had not yet been in contact with boundary layer aerosols and thus is considered as suitable to determine properties of pure ash. At that time, the layer of volcanic aerosols between $2.6 \mathrm{~km}$ and $3.5 \mathrm{~km}$ shows no wavelength dependence of $\alpha_{\mathrm{p}}$ at $355 \mathrm{~nm}$ and $532 \mathrm{~nm}$ within the error bars (Fig. 5), the Angström exponent $\kappa$ (not shown) is on average $\kappa=-0.11 \pm 0.18$, indicating large particles. The profiles of the particle backscatter coefficient $\beta_{\mathrm{p}}$ (Fig. 6) in the volcanic layer show the same spectral behavior as $\alpha_{\mathrm{p}}$ (Fig. 5). As a consequence, the lidar ratio is height-independent within the volcanic layer with values of $50<S_{\mathrm{p}}<60 \mathrm{sr}$ at $355 \mathrm{~nm}$ and $45<S_{\mathrm{p}}<55 \mathrm{sr}$ at $532 \mathrm{~nm}$. To get the linear depolarization ratio not only at $532 \mathrm{~nm}$, but also at $355 \mathrm{~nm}$, additional measurements with POLIS were performed. This implies the retrieval of $\beta_{\mathrm{p}}$ at $355 \mathrm{~nm}$ as is evident from Eq. (2). Note the excellent agreement of $\beta_{\mathrm{p}}$-retrievals derived from POLIS and MULIS data, respectively, in the common overlap region, and the extension of the profile towards the surface in case of POLIS measurements. The combination of both data-sets shows that $\delta_{\mathrm{p}}$ of the lofted layer is between $0.35<\delta_{\mathrm{p}}<0.37$ and wavelength independent, with a layer mean value of $\delta_{\mathrm{p}}=0.35 \pm 0.02$ at $355 \mathrm{~nm}$ and $\delta_{\mathrm{p}}=0.37 \pm 0.02$ at $532 \mathrm{~nm}$. These large values clearly indicate nonspherical particles and suggest a large fraction of glass- and mineral aerosols. The optical properties of the boundary layer below the ash plume are considerably different: $\alpha_{\mathrm{p}}$ is significantly decreasing with wavelength. The corresponding mean $\kappa$ is $\kappa=1.3 \pm 0.5$. This spectral behavior is typical for small particles. The corresponding lidar ratio ranges between $60<S_{\mathrm{p}}<80 \mathrm{sr}$ and does not depend on wavelength taking into account the error bars of the retrieval. The values of $\delta_{\mathrm{p}}$ are quite low and between $0.01<\delta_{\mathrm{p}}<0.02$, which is a clear indication of spherical particles.

As long as the volcanic layer was decoupled from the boundary layer, i.e. before 17 April 12:00 UTC, these $\delta_{\mathrm{p}}$-values are confirmed when different time slots are evaluated (see Fig. 7). In the boundary layer, not yet influenced by the ash, $\delta_{\mathrm{p}}$ was consistently low as mentioned above. We want to emphasize that only at the beginning of the event (until 17 April 11:00 UTC) an optically thick volcanic ash layer with extinction coefficients of $\alpha_{\mathrm{p}}>0.5 \mathrm{~km}^{-1}$ was observed over Maisach (Fig. 7). Between 05:00 UTC and 11:00 UTC the maximum extinction coefficient at $532 \mathrm{~nm}$ exceeds the corresponding values of the boundary value (see also Fig. 5, left panel). Such conditions are in general quite rare over the Munich area. In 

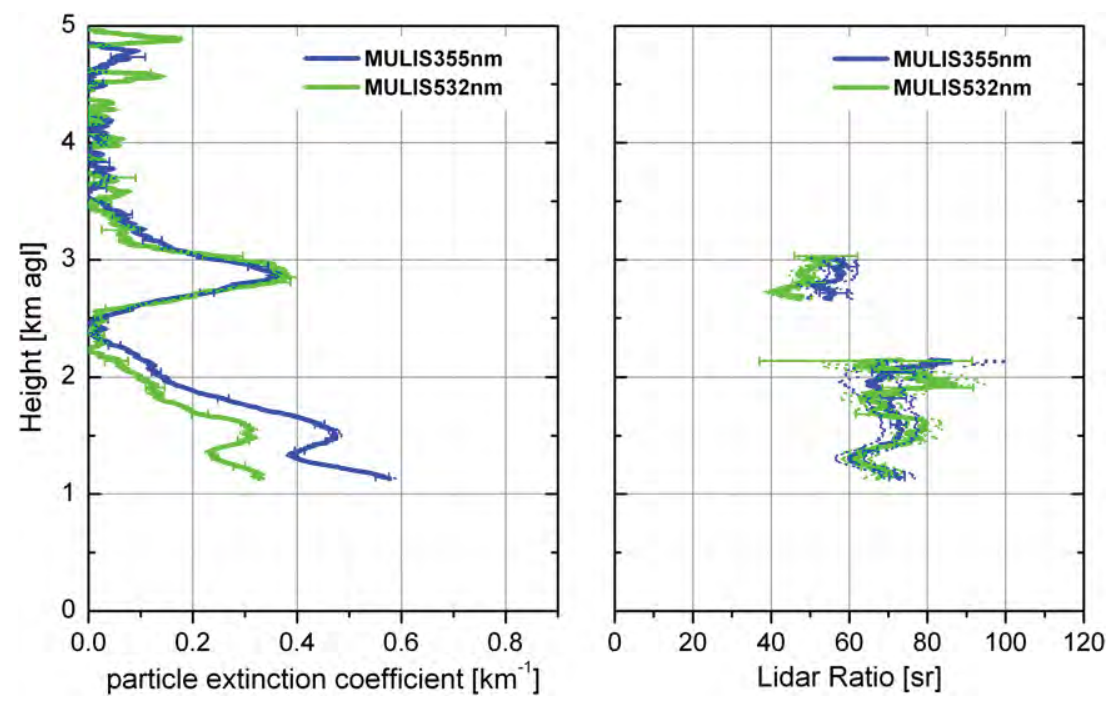

Fig. 5. Profiles of the extinction coefficient and lidar ratio at $355 \mathrm{~nm}$ and $532 \mathrm{~nm}$ derived with MULIS at Maisach on 17 April 2010 between 01:30 and 02:40 UTC. The signals were smoothed with a window length of $280 \mathrm{~m}$. The error bars indicate the statistical error, the dotted lines the systematic error.

the following, ash layers were either optically very thin - and thus less relevant for air traffic - or mixed into the boundary layer. During 17 April 2010 the volcanic ash layer descended, and in the late afternoon the ash layer started to entrain into the boundary layer as already shown in Fig. 1. To illustrate the process of mixing in a quantitative way, Fig. 7 displays the temporal development of the aerosol profiles in terms of hourly and half-hourly profiles of $\alpha_{\mathrm{p}}$ and $\delta_{\mathrm{p}}$. Note, that the $\alpha_{\mathrm{p}}$-profiles are derived from the Fernald algorithm applying lidar ratios from the Raman method. As a result, profiles from about $100 \mathrm{~m}$ above ground are obtained.

It is obvious, that the optical properties change is depending on the state of mixture. Between 12:00 UTC and 16:00 UTC the depolarization ratio began to decrease gradually. Thereafter $\delta_{\mathrm{p}}$ of the lofted layer rapidly decreased, whereas in the boundary layer $\delta_{\mathrm{p}}$ increased as a result of the mixing with the volcanic ash. As of noon it was no longer possible to investigate optical properties of pure ash. We discuss in detail the time period from 22:00 UTC to 23:00 UTC (period II, Fig. 8) and the altitude range of the boundary layer between $1.0 \mathrm{~km}$ and $1.7 \mathrm{~km}$. Data analysis (Raman method) shows that the particle extinction coefficient $\alpha_{\mathrm{p}}$ is wavelength dependent with a mean Angström exponent of $\kappa=1.1 \pm 0.2$, still indicating rather small particles. From the Raman method the mean lidar ratio in this altitude range was found to be $S_{\mathrm{p}}=56 \pm 7 \mathrm{sr}$ and $49 \pm 5 \mathrm{sr}$ at $355 \mathrm{~nm}$ and $532 \mathrm{~nm}$, respectively. As a consequence of the small differences of $S_{\mathrm{p}}$, we also see $\beta_{\mathrm{p}}$ decreasing with wavelength in the mixed layer (Fig. 9). These profiles are derived from the Fernald method, thus, the vertical coverage of the planetary boundary layer is extended towards the ground, in particular when POLIS measurements are evaluated. A wavelength dependence is also observed for the depolarization ratio: the mean values are $\delta_{\mathrm{p}}=0.12 \pm 0.02$ at $355 \mathrm{~nm}$ and $\delta_{\mathrm{p}}=0.2 \pm 0.01$ at $532 \mathrm{~nm}$, which is significantly larger. For the sake of completeness, we want to mention that above the boundary layer, i.e. heights above $2 \mathrm{~km}, \delta_{\mathrm{p}}$ is in the order of 0.2 , however, due to the low signal-to-noise ratio, the errors are quite large. Nevertheless, it is a clear evidence of the presence of volcanic ash throughout the troposphere. As described
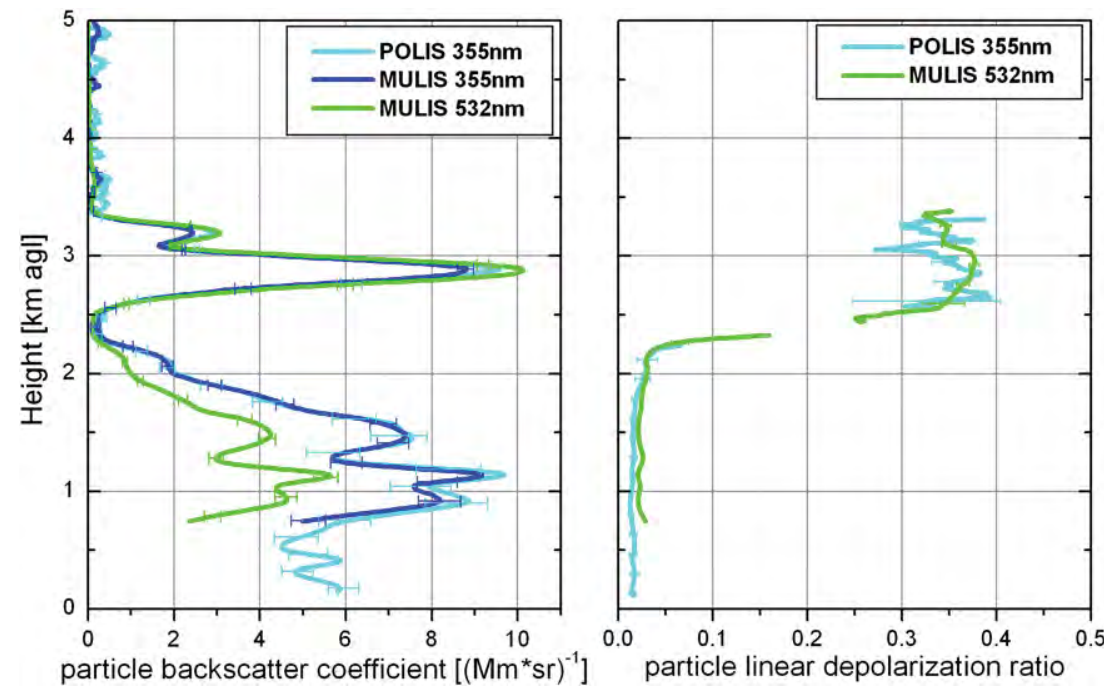

Fig. 6. Profiles of particle backscatter coefficient and particle linear depolarization ratio at $355 \mathrm{~nm}$ and $532 \mathrm{~nm}$ for 17 April 2010, 01:40-02:30 UTC (period I), derived from POLISand MULIS-measurements. The smoothing window-length was $80 \mathrm{~m}$. The error bars indicate the systematic errors. 
linear particle depolarization ratio
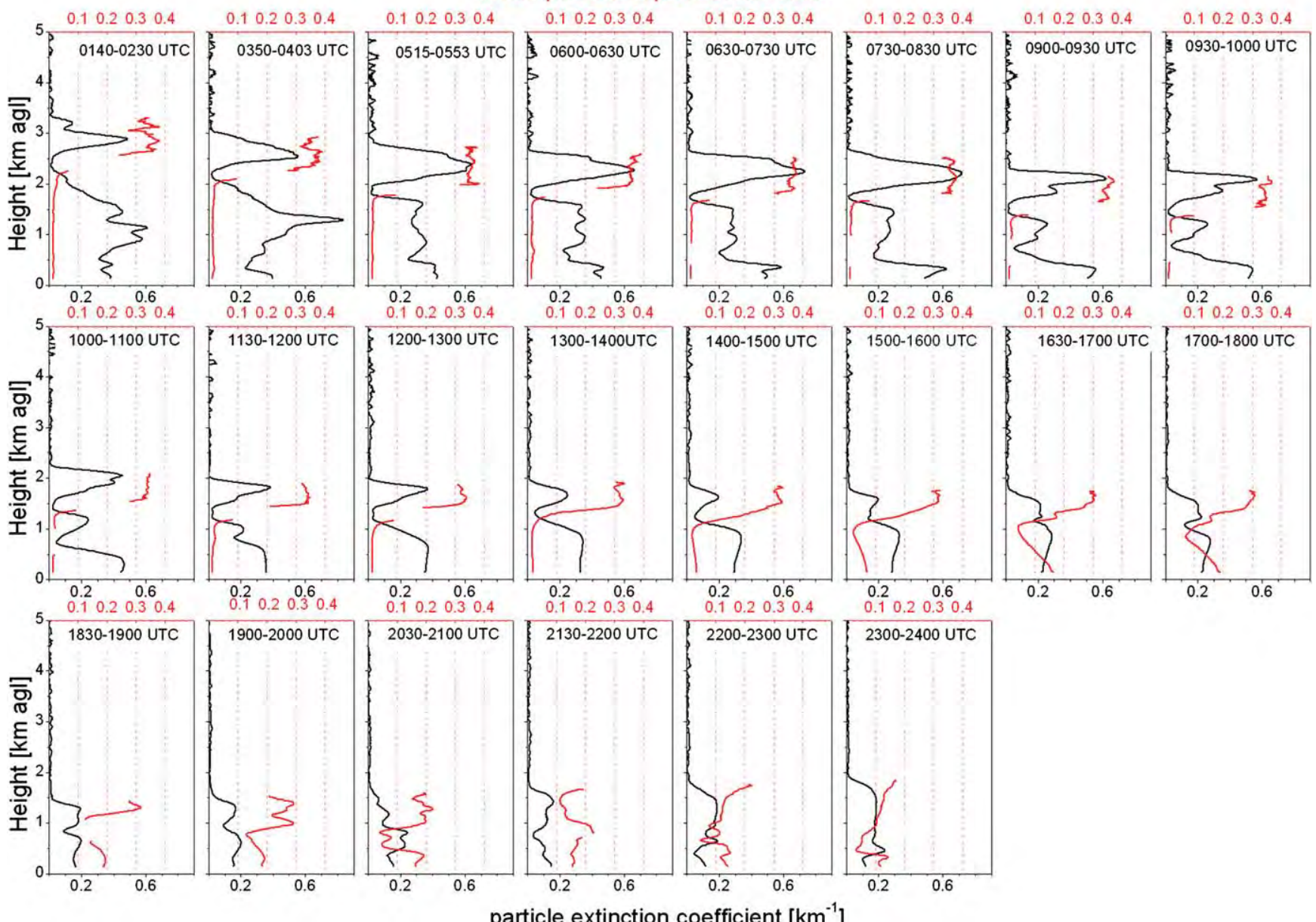

Fig. 7. Half-hourly and hourly profiles of the extinction coefficient (Klett method) and the particle linear depolarization ratio at $355 \mathrm{~nm}$ derived with POLIS at Maisach on 17 April 2010. The smoothing window-length was $80 \mathrm{~m}$.

in Section 2 a mixture of ash with boundary layer aerosols can be characterized if profiles of $\beta_{\mathrm{p}}$ and $\delta_{\mathrm{p}}$ are measured, and if the depolarization ratios of the two contributing components are known. In the following we apply this approach to the aerosol mixture of period II. The required input and the resulting profiles are shown in Fig. 10. Note, that measurements of POLIS are used. The left panel of Fig. 10 displays the measured $\delta_{\mathrm{v}}$ and $\delta_{\mathrm{p}}$ (calculated according to Eq. (2)). The measured backscatter coefficient $\beta_{\mathrm{p}}$ is
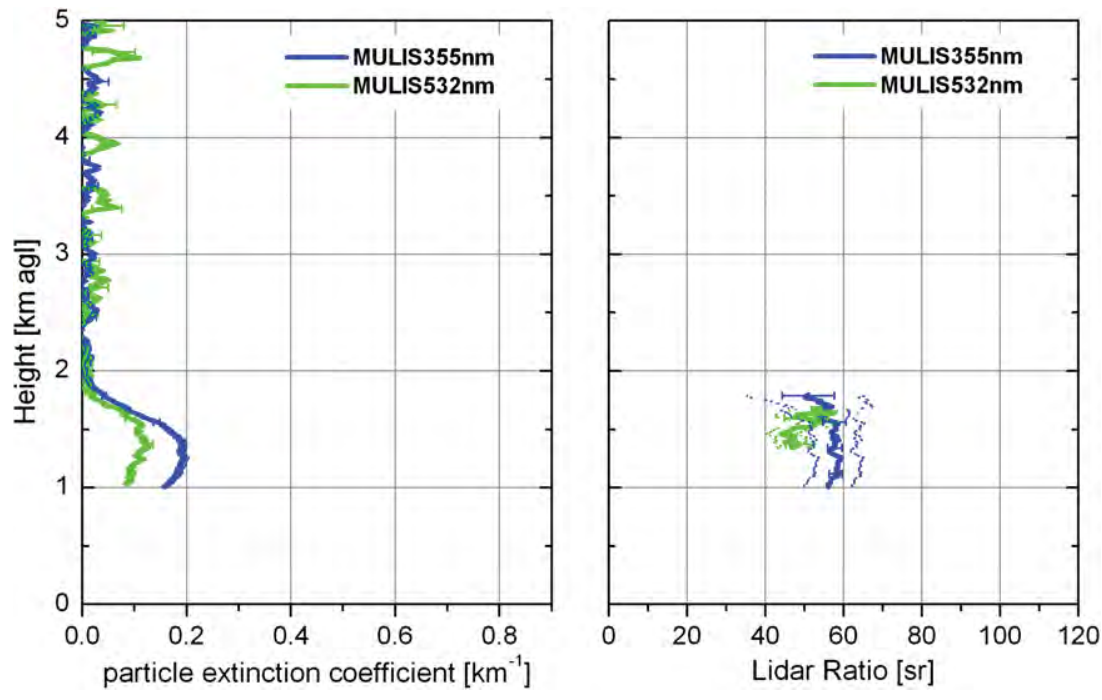

Fig. 8. Same as Fig. 5 but for 17 April 2010 between 22:00 and 23:00 UTC (period II). 

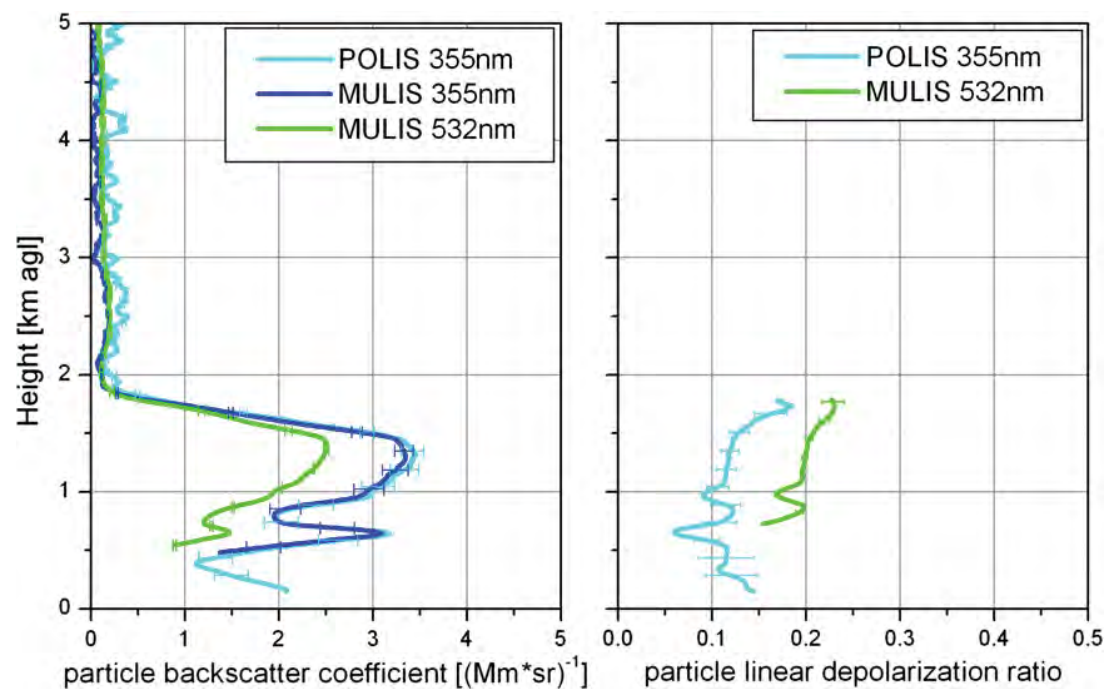

Fig. 9. Same as Fig. 6 but for 17 April 2010 between 22:00 and 23:00 UTC (period II).
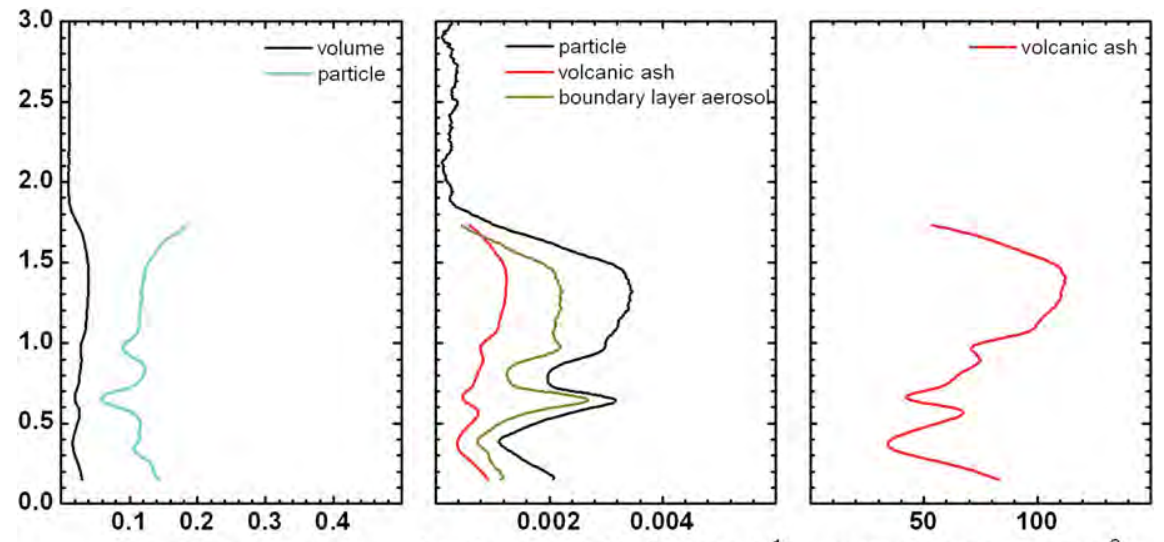

lin. depol. ratio

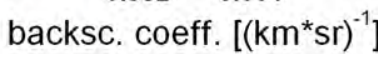

\section{mass conc. $\left[\mu \mathrm{g} / \mathrm{m}^{-3}\right]$}

Fig. 10. Analysis of POLIS measurements (period II) at $355 \mathrm{~nm}$ of depolarization ratio (left panel), total backscatter coefficient (middle panel - black line), and ash- and boundary layer aerosol related backscatter coefficient (middle panel - red and dark yellow lines), and ash mass concentration (right panel). (For interpretation of the references to colour in this figure legend, the reader is referred to the web version of this article.)
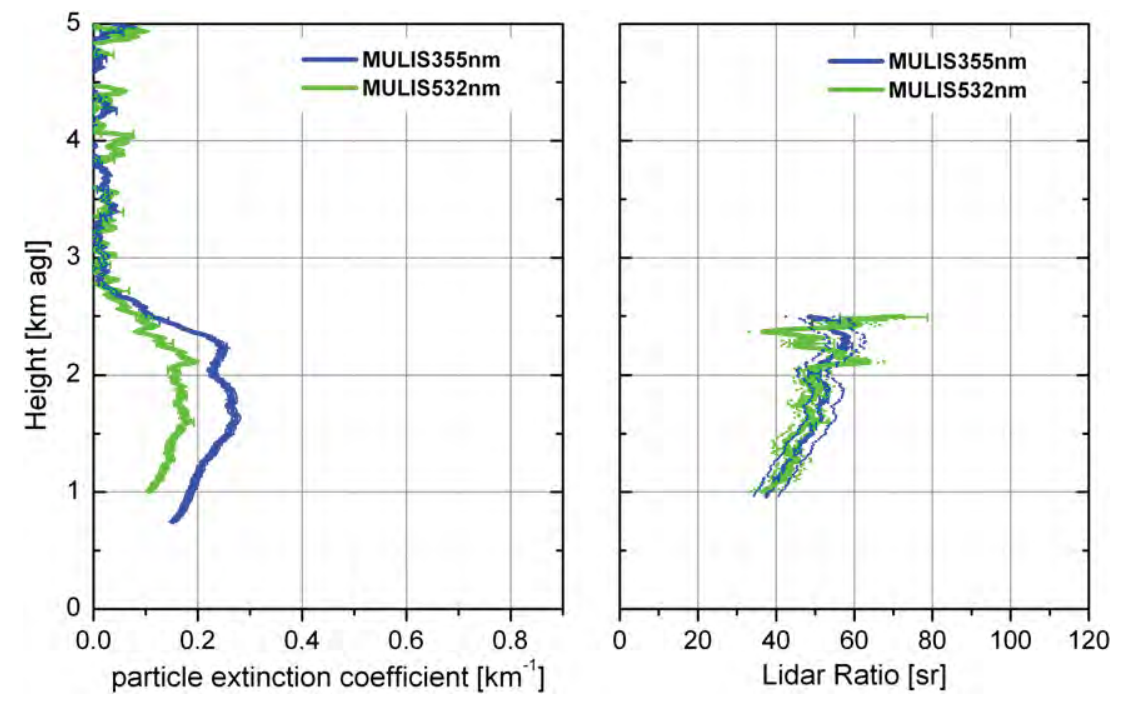

Fig. 11. Same as Fig. 8 but for 20 April 2010 between 01:00 and 02:50 UTC (period III). 

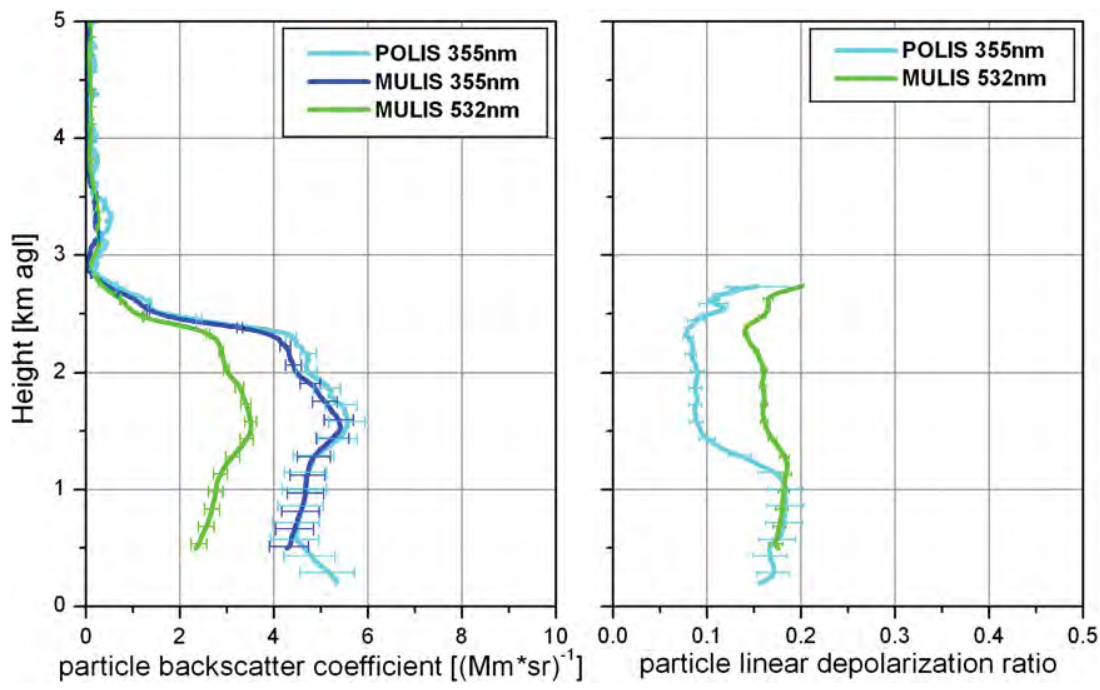

Fig. 12. Same as Fig. 9 but for 20 April 2010 between 01:00 and 02:50 UTC (period III).

shown in the center panel (black line). With this input and using Eq. (4), the backscatter coefficients of the ash $\beta_{\mathrm{a}}$ and boundary layer aerosol ("non-ash") $\beta_{\text {na }}$ are retrieved. As a result, the mean ash contribution to the backscatter coefficient of the boundary layer $(0.2-1.6 \mathrm{~km})$ is $\varepsilon_{\mathrm{b}}=0.34$. If we assume an uncertainty of \pm 0.02 for $\delta_{\mathrm{a}}$ and of \pm 0.01 for $\delta_{\text {na }}$, the error of $\varepsilon_{\mathrm{b}}$ is 0.04 . The mass concentration of volcanic ash is determined using Eq. (5). It reaches its maximum in an altitude between 1.3 and $1.5 \mathrm{~km}$ and is about $M_{\mathrm{a}}=110 \mathrm{gm}^{-3}$. According to Gasteiger et al. (2011), the uncertainty of $M_{\mathrm{a}}$ is approximately $40 \%$.

We applied the retrieval of the mass concentration also on profiles of $\beta_{\mathrm{p}}$ and $\delta_{\mathrm{p}}$ at $532 \mathrm{~nm}$ (MULIS). The deviation of the retrieved $M_{\mathrm{a}}$ at $532 \mathrm{~nm}$ from the $M_{\mathrm{a}}$ retrieved at $355 \mathrm{~nm}$ was about $10 \%$, illustrating the applicability of the ash and boundary layer aerosol properties from the morning of 17 April for the type separation of the aerosol in the evening of this day. Furthermore, the plausibility of this approach is supported by the fact that the lidar ratios modeled for the mixtures are in good agreement with the lidar ratios from the measurements. The second example for the characterization of aerosol mixtures refers to period III (20 April, 01:00 UTC to 02:50 UTC). In contrast to the previous example we expect a significant contribution of sulfur dioxide in the aerosols. The volume depolarization ratio $\delta_{\mathrm{v}}$ is larger than 0.1 at $532 \mathrm{~nm}$ as already shown in Fig. 3, indicating that volcanic particles must have been present in the boundary layer. The aerosol load was high throughout the boundary layer up to $2.5 \mathrm{~km}$ as can be seen from the particle extinction coefficient profiles (Fig. 11, left panel) with $\alpha_{\mathrm{p}}=0.1 \mathrm{~km}^{-1}$ at $532 \mathrm{~nm}$.

As can be seen from $\delta_{\mathrm{p}}$ (Fig. 12, right panel), the boundary layer consists of two sub-layers that show quite different optical properties. Accordingly, we focus on two height ranges, the first between $0.5 \mathrm{~km}$ and $1.2 \mathrm{~km}$, and the second between $1.5 \mathrm{~km}$ and $2.4 \mathrm{~km}$. Note, that with respect to the lower range, we rely on the $\alpha_{\mathrm{p}^{-}}$and $\beta_{\mathrm{p}}$-profiles retrieved by means of the Fernald inversion with $S_{\mathrm{p}} \sim 40 \mathrm{sr}$ as suggested from extrapolation of the profiles shown in Fig. 11 (right panel). For the upper layer the Raman method could be applied; the $\alpha_{\mathrm{p}}$-profiles is shown in Fig. 11 (right panel). The wavelength dependence of $\alpha_{\mathrm{p}}$ is described by a mean Angström exponent of $\kappa=1.5 \pm 0.1$ in the lower layer (not shown) and $\kappa=1.1 \pm 0.4$ in the upper layer, respectively, suggesting larger particles in the upper layer. The corresponding lidar ratio is wavelength independent and rather low with $S_{\mathrm{p}}=40 \mathrm{sr}$ in the lower layer increasing to $45<S_{\mathrm{p}}<60$ sr in the upper layer. The most interesting feature of the optical characterization is, however, the depolarization ratio. The depolarization ratio $\delta_{\mathrm{p}}$ (Fig. 12) within the lower layer (below $1.2 \mathrm{~km}$ ) shows no wavelength dependence with mean values of $\delta_{\mathrm{p}}=0.18 \pm 0.02$. In the upper layer $\delta_{\mathrm{p}}$ is clearly different with mean values of $\delta_{\mathrm{p}}=0.08 \pm 0.01$ at $355 \mathrm{~nm}$, but $\delta_{\mathrm{p}}=0.16 \pm 0.01$ at $532 \mathrm{~nm}$, i.e., not only the absolute values change, but also the wavelength dependence. This strong change of $\delta_{\mathrm{p}}$ suggest a significant modification of the micro-physical properties of the particle ensemble. It is likely that the relative humidity is at least one of the reasons for this behavior. Measurements of the radiosonde at Oberschleiheim at 00 UTC (Fig. 13) show, that in the

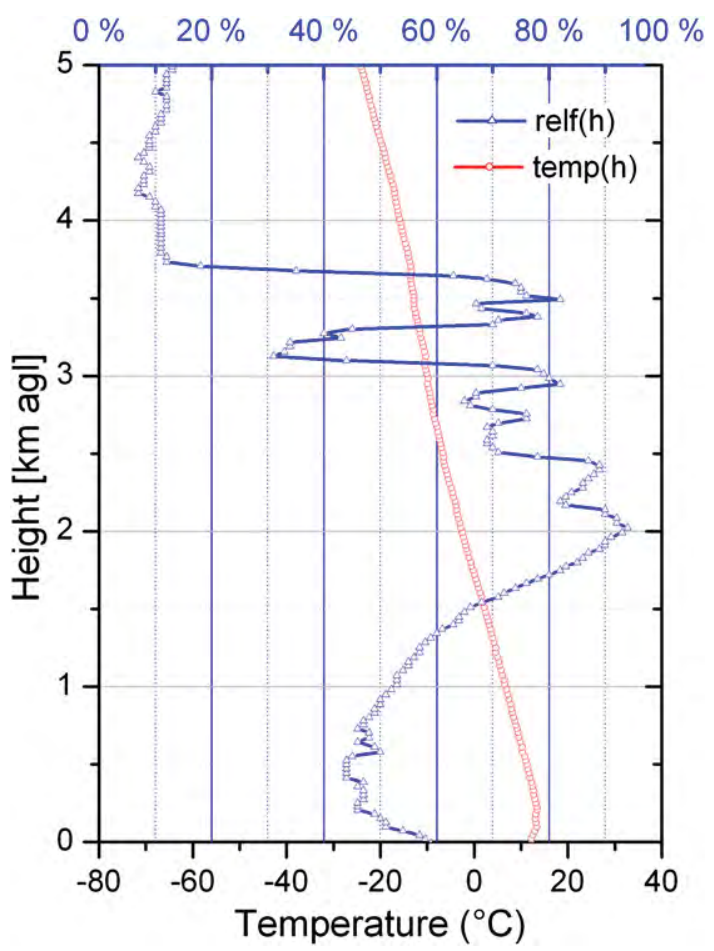

Fig. 13. Profiles of relative humidity and temperature derived from radiosonde measurements at Oberschleißheim on 20 April 2010 at 00 UTC. 

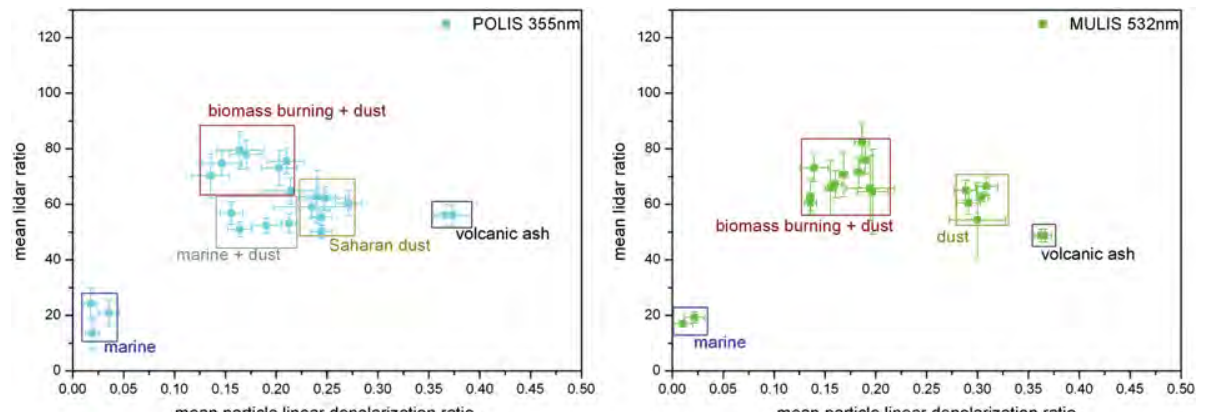

Fig. 14. Particle lidar ratio vs. particle linear depolarization ratio for different aerosol types at $355 \mathrm{~nm}$ (left) and $532 \mathrm{~nm}$ (right).

lower layer the relative humidity is below $50 \%$, whereas it is larger than $70 \%$ in the upper layer, i.e. heights above $1.5 \mathrm{~km}$. We assume that - due to the higher relative humidity - the upper layer contains a larger number of spherical particles than the lower layer, and thus the depolarization ratio $\delta_{\mathrm{p}}$ decreases. This statement implies, that hygroscopic particles must be present. Whether they are sulfuric acid droplets, hygroscopic species attached to the ash particles or locally produced aerosols, must remain speculation as no in-situ chemical analyses are available. It is remarkable that the decrease at $532 \mathrm{~nm}$ is only moderate, whereas the decrease at $355 \mathrm{~nm}$ is considerable. This may be explained if we assume that the hygroscopic droplets grow to sizes still small enough that primarily backscattering at $355 \mathrm{~nm}$ is enhanced but not at $532 \mathrm{~nm}$. Then, the decrease of $\delta_{\mathrm{p}}$ would be stronger at the shorter wavelength. For relative humidities closer to $100 \%$, the size of the hygroscopic droplets might come to an order of magnitude where backscattering at $532 \mathrm{~nm}$ also increases and consequently $\delta_{\mathrm{p}}$ at $532 \mathrm{~nm}$ decreases as well. The slight decrease of $\delta_{\mathrm{p}}$ at $532 \mathrm{~nm}$ towards the top of the upper layer, where the relative humidity reaches its maximum, might support this hypothesis, however, no evidence is available. Nevertheless, we feel that $\delta_{\mathrm{p}}$ retrieved from the lidar measurements rather suggests the presence of small hygroscopic particles such as sulfuric acid particles than large mineral or glass particles with hygroscopic attachments. The fact that throughout both layers $\delta_{\mathrm{p}}$ is quite high is attributed to the presence of hydrophobic non-spherical ash particles. Sulfuric acid droplets enlarge steadily with increasing relative humidity (Salby, 1996), while ammonium sulfate droplets show hygroscopic growth when the relative humidity exceeds a, threshold of approximately 70\% (Kaaden et al., 2009; Carrico et al., 2003). The type separation approach (Section 2) can not be applied on the profiles of $\beta_{\mathrm{p}}$ and $\delta_{\mathrm{p}}$ from 20 April 2010 because the properties of the individual aerosol components are unknown. Using the ash and the boundary layer aerosol properties from 17 April gives inconsistent results. E.g., below $1.5 \mathrm{~km}$, the lidar ratio $S_{\mathrm{p}}$ is lower than the $S_{\mathrm{p}}$ of the individual aerosol components from 17 April, showing that aerosol types have changed from 17 April to 20 April. Reasons could be, e.g., removing of the largest ash particles by gravitational settling, other source regions of the boundary layer aerosol, or advection of sulfuric acid droplets or ammonium sulfate droplets from the volcano, possibly related to temporal changes of the type of the eruption.

\section{Aerosol classification}

As the lidar ratio $S_{\mathrm{p}}$ and the particle linear depolarization ratio $\delta_{\mathrm{p}}$ are intensive aerosol properties, they only depend on the type of aerosol and not on its amount. It is well known that $S_{\mathrm{p}}$ and $\delta_{\mathrm{p}}$ are quite different for different types of aerosols (see e.g. Sakai et al.,
2010; Groß et al., 2011b); some of them additionally show a wavelength dependence of the properties. Therefore, they are an appropriate tool to distinguish different types of aerosols. However, the corresponding values for volcanic ash have not yet been assessed. Our optical characterization of the pure ash layer discussed above may fill this gap. Consequently, we have plotted the lidar ratio $S_{\mathrm{p}}$ vs. the particle linear depolarization ratio $\delta_{\mathrm{p}}$ at $355 \mathrm{~nm}$ (Fig. 14 left plot, POLIS-measurements) and at $532 \mathrm{~nm}$ (Fig. 14 right plot, MULIS-measurements). Our additional measurements concerning marine aerosols, Saharan dust and biomass burning aerosols were performed during the SAMUM field experiments in 2006 and 2008 (Groß et al., 2011b). Based on pairs of $S_{\mathrm{p}}$ and $\delta_{\mathrm{p}}$, volcanic ash can clearly be distinguished from other types of aerosols; only the differences to Saharan dust are comparably small. At $355 \mathrm{~nm}$ the lidar ratios of Saharan dust and volcanic aerosols are similar, however, $\delta_{\mathrm{p}}$ is quite different with $\delta_{\mathrm{p}}=0.24$ for Saharan dust but $\delta_{\mathrm{p}}=0.37$ for volcanic ash. This highlights the benefit of measurements of the depolarization ratio. As a conclusion, the discrimination of dust and ash is possible. At $532 \mathrm{~nm}$ the separation of the " $\mathrm{S}_{\mathrm{p}}$ clusters" is small. The ranges of $S_{p}$-values even slightly overlap for large measurement errors. Although the differences of $\delta_{\mathrm{p}}$ are smaller than in the case of $355 \mathrm{~nm}, \delta_{\mathrm{p}}$ shows its potential to discriminate the two aerosol types. However, it might become critical, especially when the retrieval errors are large, as can be the case for low aerosol load. It is obvious that additional measurements of $\delta_{\mathrm{p}}$ at $355 \mathrm{~nm}$ would help to solve this problem.

\section{Discussion and conclusion}

The eruption of the Eyjafjallajökull in April 2010 provided an excellent test bed to investigate optical properties of ash layers and to investigate differences to other aerosol types, as large amounts of particles of the volcanic emission were transported over Europe. With the European lidar network EARLINET an adequate infrastructure for this purpose was available, in particular, as only lidars can provide range resolved information. In this paper we focus on our lidar measurements at Maisach, Germany, as at this site two advanced lidar systems of EARLINET are located. They provide an exceptional set of optical data, in particular, they include particle linear depolarization ratios $\delta_{\mathrm{p}}$ and lidar ratios $S_{\mathrm{p}}$ at two wavelengths. This fact allows the development of criteria for aerosol type discrimination - based on single- or dualwavelengths data sets. A prerequisite to reach this objective, measurements of pure volcanic ash must be available. This condition was fulfilled as we were monitoring the volcanic plume before it became mixed into the planetary boundary layer. The volcanic aerosols were first observed over Maisach on the evening of 16 April 2010 as a distinct layer in a height of $7 \mathrm{~km}$. Though this layer slowly descended with time it was not in contact with the 
planetary boundary layer before the afternoon of the next day. For this layer of pure ash wavelength independent linear depolarization ratios between $0.35<\delta_{\mathrm{p}}<0.38$ were observed. These values are among the largest ever measured for tropospheric aerosols. Thus, $\delta_{\mathrm{p}}$ can be used as criterion for the identification of volcanic ash, in particular at $355 \mathrm{~nm}$, where the differences to other aerosol types are most significant. Our investigations show that $S_{\mathrm{p}}$ is hardly suitable to distinguish volcanic ash from other types, especially, as the lidar ratio of dust is quite similar. We conclude that (dual-wavelength) depolarization ratios are the preferential quantity for ash identification. The assessment of the depolarization ratio of ash, $\delta_{\mathrm{a}}$, is not only useful for aerosol typing, it also allows to determine relevant information on the mixing state of aerosol layers consisting of two different types of particles, one of them being volcanic ash. This approach was tested for two time slices, when the ash from the Eyjafjallajökull was entrained into the planetary boundary layer, demonstrating the potential but also caveats. After the entrainment of the ash-loaded air-masses into the boundary layer on 17 April, the observed optical properties of this aerosol mixture can be explained by mixing the optical properties of the ash and the boundary layer aerosol from the morning of the same day. Using the known linear depolarization ratio $\delta_{\mathrm{p}}$ of the two aerosol types, the contribution of each aerosol type can be determined and the mass concentration of volcanic ash in the boundary layer can be estimated. Based on this procedure we estimated a mass concentration of up to $\sim 110 \mathrm{gm}^{-3}$ of volcanic ash in the boundary layer at the evening of 17 April 2010. Applied on measurements of ash mixed with boundary layer aerosol on 20 April 2010, the type separation approach using optical properties of the individual aerosol types from 17 April did not give consistent results; this suggests that the aerosol types changed from 17 April to 20 April. The most remarkable result of our studies is that, under certain conditions, $\delta_{\mathrm{p}}$ shows a wavelength dependence with lower values at $355 \mathrm{~nm}$ when volcanic ash is mixed with other types of aerosols. Comparisons with radiosondes launched at Oberschleiheim (22 km east of Maisach) led to the assumption that $\delta_{\mathrm{p}}$ and the relative humidity may be correlated, and thus the observed behavior of $\delta_{\mathrm{p}}$ may indicate the presence of hygroscopic particles. The spectral dependence of $\delta_{\mathrm{p}}$ might have the potential to extract some information on the size of the hygroscopic particles.

\section{Acknowledgment}

The authors gratefully acknowledge the NOAA Air Resources Laboratory (ARL) for the provision of the HYSPLIT transport and dispersion model and READY website (http://www.arl.noaa.gov/ ready.php) used in this publication. Furthermore, the fiancial support for the improvement of the EARLINET infrastructure by the European Commission under grant RICA-025991 is gratefully acknowledged.

\section{References}

Ansmann, A., Tesche, M., Groß, S., Freudenthaler, V., Seifert, P., Hiebsch, A., Schmidt, J., Wandinger, U., Mattis, I., Müller, D., Wiegner, M., 2010. The 16 April 2010 major volcanic ash plume over Central Europe: EARLINET lidar and AERONET photometer observations at Leipzig and Munich, Germany. Geophysical Research Letters 37, 5.

Ansmann, A., Wandinger, U., Riebesell, M., Weitkamp, C., Michaelis, W., 1992. Independent measurement of extinction and backscatter profiles in cirrus clouds by using a combined Raman elastic-backscatter lidar. Applied Optics 31, 7113.

Behrendt, A., Nakamura, T., 2002. Calculation of the calibration constant of polarization lidar and its dependency on atmospheric temperature. Optics Express 10, 805-817.

Biele, J., Beyerle, G., Baumgarten, G., 2000. Polarization lidar: correction of instrumental effects. Optics Express 7, 427-435.
Boesenberg, J., 2003. EARLINET: A European Aerosol Research Lidar Network to Establish an Aerosol Climatology. Max-Planck-Institut fuer Meteorologie, Hamburg. Report 248

Carrico, C.M., Kus, P., Rood, M.J., Quinn, P.K., Bates, T.S., 2003. Mixtures of pollution, dust, sea salt, and volcanic aerosol during ace-asia: radiative properties as a function of relative humidity. Journal of Geophysical Research 108 (D23), 8650.

Emeis, S., Junkermann, W., Schäfer, K., Forkel, R., Suppan, P., Flentje, H., Gilge, S., Fricke, W., Wiegner, M., Freudenthaler, V., Groß, S., Ries, L., Meinhardt, F., Münkel, C., Obleitner, F., 2010. Spatial structure and dispersion of the 16/17 april 2010 volcanic ash cloud over Germany. Atmospheric Chemistry and Physics Discussions 10, 26117-26155.

Fernald, F.G., 1984. Analysis of atmospheric lidar observations: some comments. Applied Optics 23, 652-653.

Flentje, H., Claude, H., Elste, T., Gilge, S., Köhler, U., Plass-Dülmer, C., Steinbrecht, W., Thomas, W., Werner, A., Fricke, W., 2010. The Eyjafjallajkull eruption in April 2010 - detection of volcanic plume using in-situ measurements, ozone sondes and lidar-ceilometer proles. Atmospheric Chemistry and Physics 10, 10085-10092.

Freudenthaler, V., Esselborn, M., Wiegner, M., Heese, B., Tesche, M., Ansmann, A., Müller, D., Althause, D., Wirth, M., Fix, A., Ehret, G., Knippertz, P., Toledano, C., Gasteiger, J., Garhammer, M., Seefeldner, M., 2009. Depolarization ratio profiing at several wavelengths in pure Saharan dust during SAMUM 2006. Tellus B 61, $165-179$

Gasteiger, J., Groß, S., Freudenthaler, V., Wiegner, M., 2011. Volcanic ash from Iceland over Munich: mass concentration retrieved from groundbased remote sensing measurements. Atmospheric Chemistry and Physics 11, 2209-2223.

Groß, S., Freudenthaler, V., Toledano, C., Seefeldner, M., Wiegner, M., 2008. Minilidar measurements of particle depolarization and Raman scattering of Saharan-dust and biomass burning at $355 \mathrm{~nm}$ during SAMUM 2. In: Proceedings Of 24th International Laser Radar Conference, Boulder, USA, pp. 23-27. June 2008 S04P-10.

Groß, S., Gasteiger, J., Freudenthaler, V., Schnell, F., Wiegner, M., 2010. Characterization of the Eyjafjallajökull ash-plume by means of lidar measurements over the Munich EARLINET-site. In: Proceedings of SPIE, vol. 7832-20, pp. 20-23. Toulouse, France, September 2010

Groß, S., Wiegner, M., Freudenthaler, V., Toledano, C., 2011a. Lidar ratio of Saharan dust over Cape Verde Islands: assessment and error calculation. Journal of Geophysical Research. doi:10.1029/2010JD015435.

Groß, S., Tesche, M., Freudenthaler, V., Toledano, C., Wiegner, M., Ansmann, A., Althausen, D. Seefeldner, M., 2011b. Characterization of Saharan dust, marine aerosols and mixtures of biomass burning aerosols and dust by means of multiwavelengthdepolarization- and Raman-measurmentsduring SAMUM-2. Tellus B 63. doi:10.1111/j.1600-0889.2011.00556.x.

Jaeger, H., 2005. Long-term record of lidar observations of the stratospheric aerosol layer at Garmisch-Partenkirchen. Journal of Geophysical Research 110 (D08106), 9.

Jones, A., Johnson, D., Hort, M., Devenish, B., 2007. The UK Met Office's nextgeneration atmospheric dispersion model, NAME III. In: Air Pollustion Modeling and Its Application, vol. XVII. Springer.

Kaaden, N., Massling, A., Schladitz, A., Muller, T., Kandler, K., Schütz, L., Weinzierl, B., Petzold, A., Tesche, M., Leinert, S., Deutscher, C., Ebert, M., Weinbruch, S., Wiedensohler, A., 2009. State of mixing, shape factor, number size distribution, and hygroscopic growth of the Saharan anthropogenic and mineral dust aerosol at Tinfou, Morocco. Tellus B 61, 51-63.

Magnus, T.G., Pedersen, R., Vogfjrd, K., Thorbjarnardottir, B., Jakobsdottir, S., Roberts, M.J., 2010. Eruptions of Eyjafjallajkull volcano, Iceland. EOS 91, 190-191.

Mattis, I., Seifert, P., Mller, D., Tesche, M., Hiebsch, A., Kanitz, T., Schmidt, J., Finger, F., Wandinger, U., Ansmann, A., 2010. Volcanic aerosol layers observed with multiwavelength Raman lidar over Central Europe in 2008-2009. Journal of Geophysical Research 115 (D00L04).

Ovadnevaite, J., Ceburnis, D., Plauskaite-Sukiene, K., Modini, R., Dupuy, R., Rimselyte, I., Ramonet, M., Kvietkus, K., Ristovski, Z., Berresheim, H., 2009. Volcanic sulphate and arctic dust plumes over the North Atlantic Ocean. Atmospheric Environment 43 (32), 4968-4974.

Parker, D.E., Wilson, H., Jones, P.D., Christy, J.R., Folland, C.K., 1996. The impact of mount Pinatubo on world-wide temperatures. International Journal of Climatology $16,487-497$.

Rampino, M.R., Self, S., 1982. Historic eruptions of Tambora (1815), Krakatau (1883), and Agung (1963), their stratospheric aerosols, and climatic impact. Quaternary Research 18, 127-143.

Robock, A., 2000. Volcanic eruptions and climate. Reviews of Geophysics 38, 191-219.

Sakai, T., Nagai, T., Zaizen, Y., Mano, Y., 2010. Backscattering linear depolarization ratio measurements of mineral, sea-salt, and ammonium sulfate particles simulated in a laboratory chamber. Applied Optics 49, 4441-4449.

Salby, M.L., 1996. Fundamentals of Atmospheric Physics. Academic Pr.

Sassen, K., Zhu, J., Webley, P., Dean, K., Cobb, P., 2007. Volcanic ash plume identification using polarization lidar: Augustine eruption, Alaska. Geophysical Research Letters 34 (8) L08803+.

Tesche, M., Ansmann, A., Mller, D., Althausen, D., Engelmann, R., Freudenthaler, V., Groß, S., 2009. Vertically resolved separation of dust and smoke over Cape Verde using multiwavelength Raman and polarization lidars during Saharan mineral dust experiment 2008. Journal of Geophysical Research 114 (D13202). 
Trenberth, K.E., Dai, A., 2007. Effects of mount Pinatubo volcanic eruption on the hydrological cycle as an analog of geoengineering. Geophysical Research Letters 34 (L15702).

Wang, X., Boselli, A., D’Avino, L., Pisani, G., Spinelli, N., Amodeo, A., Chaikovsky, A. Wiegner, M., Nickovic, S., Papayannis, A., 2008. Volcanic dust characterization by EARLINET during Etna's eruptions in 2001-2002. Atmospheric Environment 42 (5), 893-905.

Wiegner, M., Gasteiger, J., Groß, S., Schnell, F., Freudenthaler, V., Forkel, R., 2011 Characterization of the Eyjafjallajkull ash-plume:potential of lidar remote sensing. Physics and Chemistry of the Earth. doi:10.1016/j.pce.2011.01.006. 